\title{
Structure-based drug design studies of UDP-N- acetylglucosamine pyrophosphosrylase, a key enzyme for the control of witches' broom disease
}

\author{
Manoelito C Santos Junior ${ }^{1 *}$, Sandra Aparecida de Assis ${ }^{1}$, Aristóteles Góes-Neto ${ }^{2}$, Ângelo Amâncio Duarte , \\ Ricardo José Alves ${ }^{4}$, Moacyr Comar Junior ${ }^{5}$ and Alex Gutterres Taranto ${ }^{5}$
}

\begin{abstract}
Background: The witches' broom disease is a plague caused by Moniliophthora perniciosa in the Theobroma cacao, which has been reducing the cocoa production since 1989. This issue motivated a genome project that has showing several new molecular targets, which can be developed inhibitors in order to control the plague. Among the molecular targets obtained, the UDP-N-acetylglucosamine pyrophosphorylase (UNAcP) is a key enzyme to construct the fungal cell wall. The inhibition of this enzyme results in the fungal cell death.

Results: The results show that the molecular recognition of the enzyme with the substrates occurs mainly by hydrogen bonds between ligands and Arg116, Arg383, Gly381, and Lys408 amino acids; and few hydrophobic interactions with Tyr382 and Lys123 residues.

Conclusions: Among the compounds analyzed, the NAG5 showed the best binding energy $(-95.2 \mathrm{kcal} / \mathrm{mol})$. The next steps for the control of witches' broom plague involve the synthesis and biological evaluation of these compounds, which are in progress.
\end{abstract}

Keywords: Docking, Molecular dynamics, Pyrophosphorylase, Moniliophthora perniciosa

\section{Background}

In 1989, the economy of Bahia State in Brazil was strongly impacted and cocoa production dropped drastically because of the emergence and proliferation of the fungus Moniliophthora perniciosa, a plague known as witches' broom [1]. Consequently, Brazil began to import cocoa [2,3]. Several efforts have been made to contain the spread of witches' broom in Bahia. However, most of them have failed for several reasons, particularly the lack of genetic resistance during the initial contact with this plague [4]. The progress of the pest has been slowed using agricultural practices such as phytosanitary pruning, fertilisation and application of copper fungicides. However, the cost of fungicide application has made these practices impossible for most farmers [4,5]. These data motivated the search for an alternative chemical control for witches' broom.

\footnotetext{
* Correspondence: mc2500@gmail.com

1 Departamentos de Saúde, Feira de Santana 44031-460, Feira de Santana-BA, Brazil Full list of author information is available at the end of the article
}

Several chemical compounds have been tested for their capacity to prevent or eradicate witches' broom. The results, however, have not been satisfactory [6]. Inhibitors of bacterial cell wall biosynthesis, such as penicillin and cephalosporin, have shown good results in the control of bacterial infections. Similarly, the cell walls of fungi are promising targets for the development of potent antifungals [7-12]. The main component of the fungal cell wall is chitin, which is formed from a key precursor denoted by UDP- $N$-acetylglucosamine. This precursor is formed by a reaction between $N$-acetylglucosamine-1-phosphate and uridine- $5^{\prime}$-triphosphate (UTP), which is catalyzed by UDP- $N$-acetylglucosamine pyrophosphorylase (UNAcP). The inhibition of UDP- $N$-acetylglucosamine formation affects the synthesis of chitin. Therefore, fungal cell wall synthesis cannot take place, resulting in fungal cell death [13-15].

The conformation of UTP in the active site of UNAcP is similar in all enzymes deposited in the Protein Data Bank (PDB) [16]. The UTP binds in the central region 
of the enzyme, making contact with a loop formed by residues from Asp221 to Leu226. The sugar moiety is stabilized by hydrogen bonds formed by Ala261 and Asp417 residues. The $\mathrm{N}$-acetyl moiety establishes hydrogen bonds with the Asn223, Glu303 and His331 and a hydrophobic interaction with Phe381 and Phe383 [16]. However, this hydrophobic pocket is not present in other enzymes in the active site of pyrophosphorylases from $M$. perniciosa [14].

This work aimed to perform studies of molecular docking followed by molecular dynamics simulations of the enzyme UDP- $N$-acetylglucosamine pyrophosphorylase from the fungus $M$. perniciosa. The goal is the development of new inhibitors of the pyrophosphorylase enzyme that can be used for management of this pathogen.

\section{Results and discussion}

Three points were determined to be important for molecular recognition by the enzyme substrate: the pentose, uracil and $\mathrm{N}$-acetylglucosaminyl moieties. In addition, the enzyme has two substrates, UTP and $N$-acetylglucosamine-1phosphate [14-17]. In analysing the molecular recognition, it can be observed that the pentose and nucleoside moieties establish hydrogen bonds with the residues of the second half of the central loop of the UNAcP (residues from Val68 to Val260). $\mathrm{N}$-acetylglucosamine is also recognized by hydrogen bonds, and it is possible to observe a hydrophobic interaction in human UNAcP that occurs between two phenylalanines (381 and 383) [16].

Information about the active site of the enzyme is essential for the development of ligands [18]. Based on<smiles>CC(=O)Nc1c(O)cccc1O[C@H]1C(O)C(CO)OC(Oc2cccc(O)c2)C1NC(C)=O</smiles><smiles>CC(=O)NC1[C@H](Oc2cccc([N+](=O)[O-])c2)O[C@H](CO)[C@H](O)[C@H]1NC(C)=O</smiles><smiles>CC(=O)NC1C(Oc2cccc(C(C)=O)c2)OC(CO)C(O)C1O</smiles><smiles>CC(=O)NC1C(Oc2cccc(C(=O)O)c2O)O[C@H](CO)C(O)[C@@H]1O</smiles><smiles>CC(=O)N[C@H]1C(O)C(O)C(CO)O[C@H]1Oc1cccc(NC[C@H]2O[C@@H](n3ccc(=O)[nH]c3=O)C(O)C2O)c1O</smiles><smiles>CC(=O)N[C@@H]1C(O)[C@H](O)[C@@H](CO)O[C@H]1Oc1cccc(C(=O)Nc2ccccc2C(=O)NCCCO)c1O</smiles>

Figure 1 Structure of the ten potential inhibitors. 
this data regarding the compounds that are molecularly recognized by the enzyme, ten potential UNAcP inhibitors were proposed for the enzyme (Figure 1). The first step of the docking studies involves a detailed analysis of the binding site and a description of all aspects in relation to affinity and selectivity [18]. The active site in the previous model built of UNAcP from M. perniciosa is highly conserved compared with the crystallographic structure 1JV1 [16]. However, the regions between 379-384 and 403-409 residues showed no similarity, which is highlighted by the hydrophobic pocket formed by residues Phe381 and Phe383. They are absent in the constructed model [14].

The second step for docking simulation is the redock of crystallographic ligand to validate the process. The conformations of redock are shown in Figure 2. As can be seen, RMS values of $0.00 \AA$ and $0.78 \AA$ were found for $\mathrm{N}$-acetylglucosamine-1-phosphate and UTP, respectively. RMS values below $2 \AA$ are considered acceptable [19-21]. These values were satisfactory, indicating that the structures were well anchored. The present spatial positioning was very near the structures that were used as references, thereby indicating that the size and location of the grid box were satisfactory. The binding energy of redocking structures, $N$-acetylglucosamine-1phosphate and UTP, was -5.3 and $-6.3 \mathrm{kcal} / \mathrm{mol}$, respectively. Table 1 shows the docking results of all compounds in the active site of UNAcP. The compound with the most affinity is NAG9 $(-9.1 \mathrm{kcal} / \mathrm{mol})$, whereas the compound with the least affinity is NAG5 $(-7.0 \mathrm{kcal} / \mathrm{mol})$. Next, the docking geometry was used for the MD simulations.

MD simulations were carried out for ten ligands. All were submitted to 8000 ps of MD simulations, as specified in the methodology. The MD determines the trajectories of representative points in the space through the numerical solution of the equations of motion [22]. The

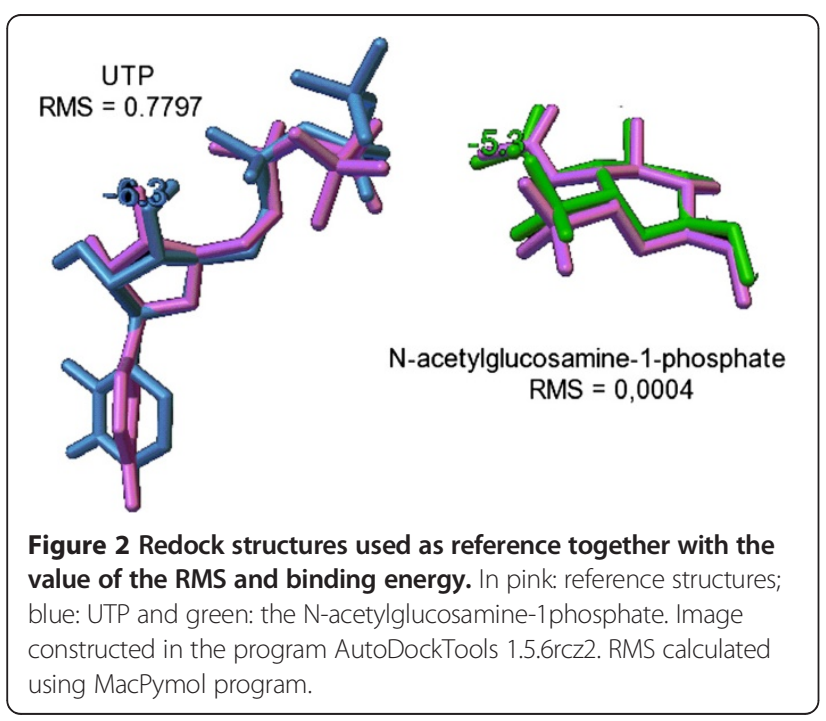

Table 1 Binding energy estimated by Autodock Vina and AMBER11

\begin{tabular}{ccc}
\hline & Binding energy (Kcal/mol) & \\
\hline Compounds & Autodock Vina & AMBER11 \\
\hline NAG1 & -7.2 & -59.0 \\
NAG2 & -7.3 & -88.2 \\
NAG3 & -7.8 & -25.5 \\
NAG4 & -7.2 & -52.1 \\
NAG5 & -7.0 & $-95,2$ \\
NAG6 & -7.9 & -8.0 \\
NAG7 & -8.0 & -72.2 \\
NAG8 & -7.7 & -17.6 \\
NAG9 & -9.1 & -83.7 \\
NAG10 & -8.8 & -22.4 \\
\hline
\end{tabular}

basic objective of this method is to observe the evolution of the system through these equations, because it is through the interactions among the particles that the system is able to maintain both mechanical and thermal equilibrium, and if there is any external perturbation, the system tends to reach a new equilibrium [22]. The results of MD are depicted in Figure 3, which shows the variation in the RMSD of $\mathrm{C} \alpha$ atoms for the protein during the simulation time. The RMSD was dependent on each complex, with the lowest variation observed for the complexes NAG4 $(3.8 \AA)$ and NAG8 $(3.8 \AA)$ and the greatest for NAG9 $(5.8 \AA)$ and NAG10 (5.8 $)$ ); the larger molecules showed the largest fluctuations. All simulations of the complex reached equilibrium after 4.000 ps of simulation. In addition, the kinetic, potential and total energies were also obtained throughout the simulations (Figure 3). As can be seen, there were no significant fluctuations. The initial increase in the kinetic energy is related to the heating step of the system; subsequently, it is kept constant during the simulation. This indicates that the temperature of the system was constant at the value determined for the study. The potential energy, and hence the total energy, remained constant throughout the trajectory, indicating a relaxation of the system; therefore, equilibrium was reached for all compounds.

The average structure from MD simulation of each compound was used to determine the binding energy. In each MD simulation, a cut was made in the equilibrium region. The average structure was separated into COMP (UNAcP-NAG), LIG (NAGs) and PTN (UNAcP), and each was, finally, optimized again. Thus, the binding energy was determined by the formula $\Delta \mathrm{G}=\mathrm{E}_{\mathrm{COMP}}-\mathrm{E}_{\mathrm{PTN}}$ -

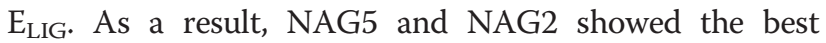
affinity for UNAcP (Table 1), differing by only $6.7 \mathrm{kcal} /$ mol. In contrast, the compound NAG6 showed the lowest interaction with UNAcP (Table 1). The docking results differ considerably from MD simulations. In docking 


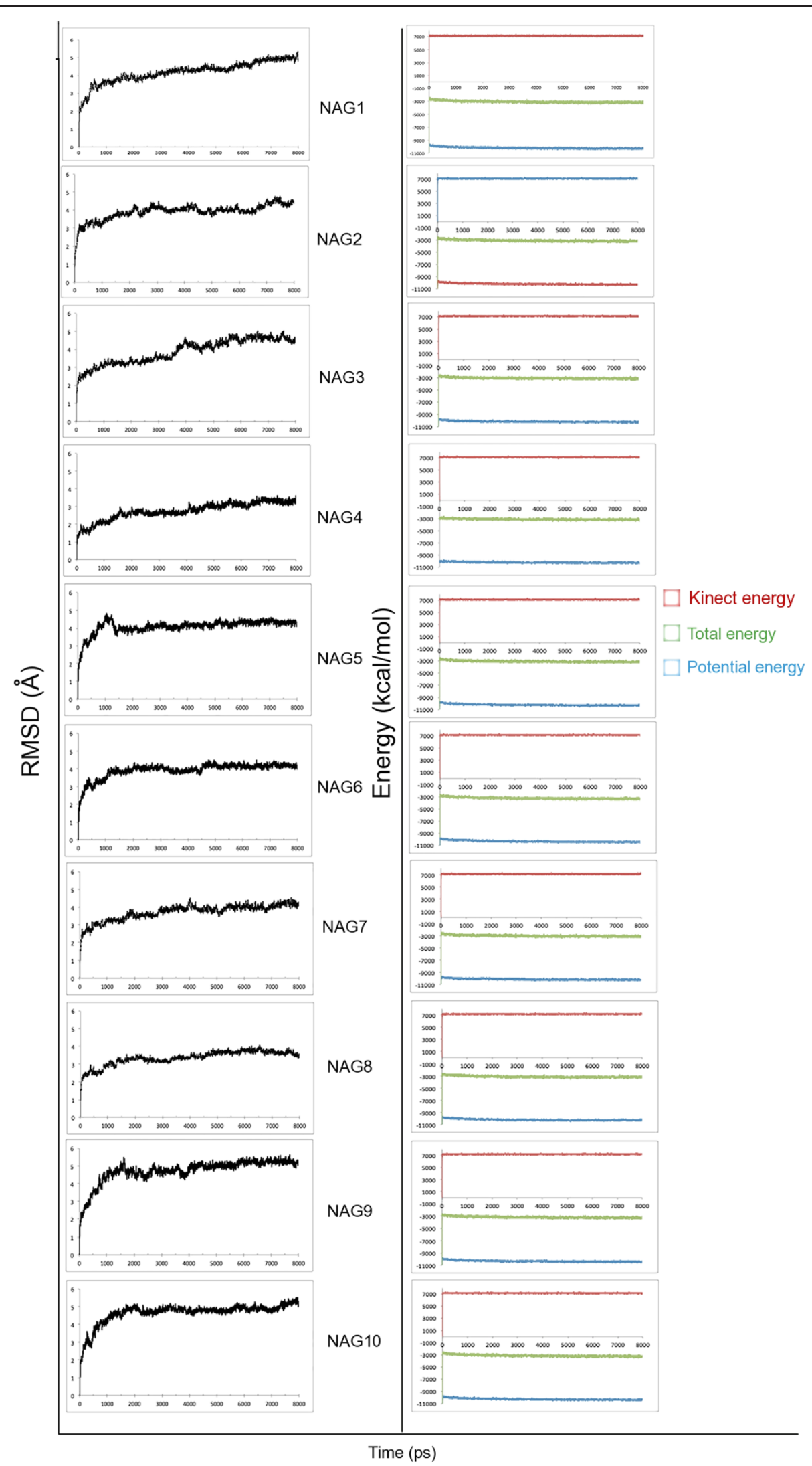

Figure 3 RMSD, total, energy and kinetic energies of then complexes after 8000ps of MD simulateion. 
methodology, only ligand is flexible in a rigid active site. This neglects the conformational changes induced by ligand. Conversely, the MD simulations permit the molecular motion of target and ligand. Hence, our docking results were refined by $\mathrm{MD}$ simulation, improving the accuracy of the model. In other words, all docking experiments should follow MD or quantum mechanics and molecular mechanics (QM/MM) calculations.

The most active compound designed (NAG5) formed with UNAcP hydrogen bonds ( $\mathrm{HB}), \pi$-cation and hydrophobic interactions. Figure 4 highlights in $2 \mathrm{D}$ and $3 \mathrm{D}$ the pharmacophoric conformation. As can be seen, the intermolecular interaction for NAG5, HB network was formed with Arg116, Gly381, Arg383 and Lys408 residues, with the distance ranging from $2.9 \AA$ to and $3.14 \AA$. The hydrophobic interaction was observed with the aromatic ring of Tyr382 with a distance of $3.85 \AA$. Moreover, the aromatic ring of NAG5 also interacted with the Lys123 through a $\pi$-cation interaction, with a distance of $3.99 \AA$. However, NAG6, the least active compound designed, while showing intermolecular interactions very similar to those of NAG5, differs in the absence of hydrogen bonds formed between vicinal hydroxyl groups (catechol) with Lys123. This result suggests the hydroxyl is important as a pharmacophoric group, but not essential for intermolecular recognition among UNAcP and inhibitors. In addition, hydrogen bonds are formed between ligand and Pro63, Gln113 and Arg353, which ranged from 2.94 $\AA 3.12 \AA$ with NAG6.

\section{Conclusions}

The search for an effective control for witches' broom has demanded much effort in recent years, mainly due to the socio-economic impact that the plague has had in the state of Bahia and other areas that were previously cocoa producers. This study was developed with a goal of finding a compound that can be used for effective control of witches' broom. For this purpose, a structurebased drug design approach was used to study the molecular recognition between UNAcP of $M$. perniciosa and substrates. Initially, the molecular target chosen was pyrophosphorylase enzyme, and ten ligands were finally designed to inhibit the enzyme and thereby prevent the development of the witches' broom fungus. Furthermore, the docking results were refined by MD simulations, improving the accuracy of the models.

The next step in developing new strategies for the control of witches' broom is the in vitro enzyme pyrophosphorylase assay of these compounds, which can be synthesized by classical carbohydrate chemistry. This work is in progress and will be reported in due time.

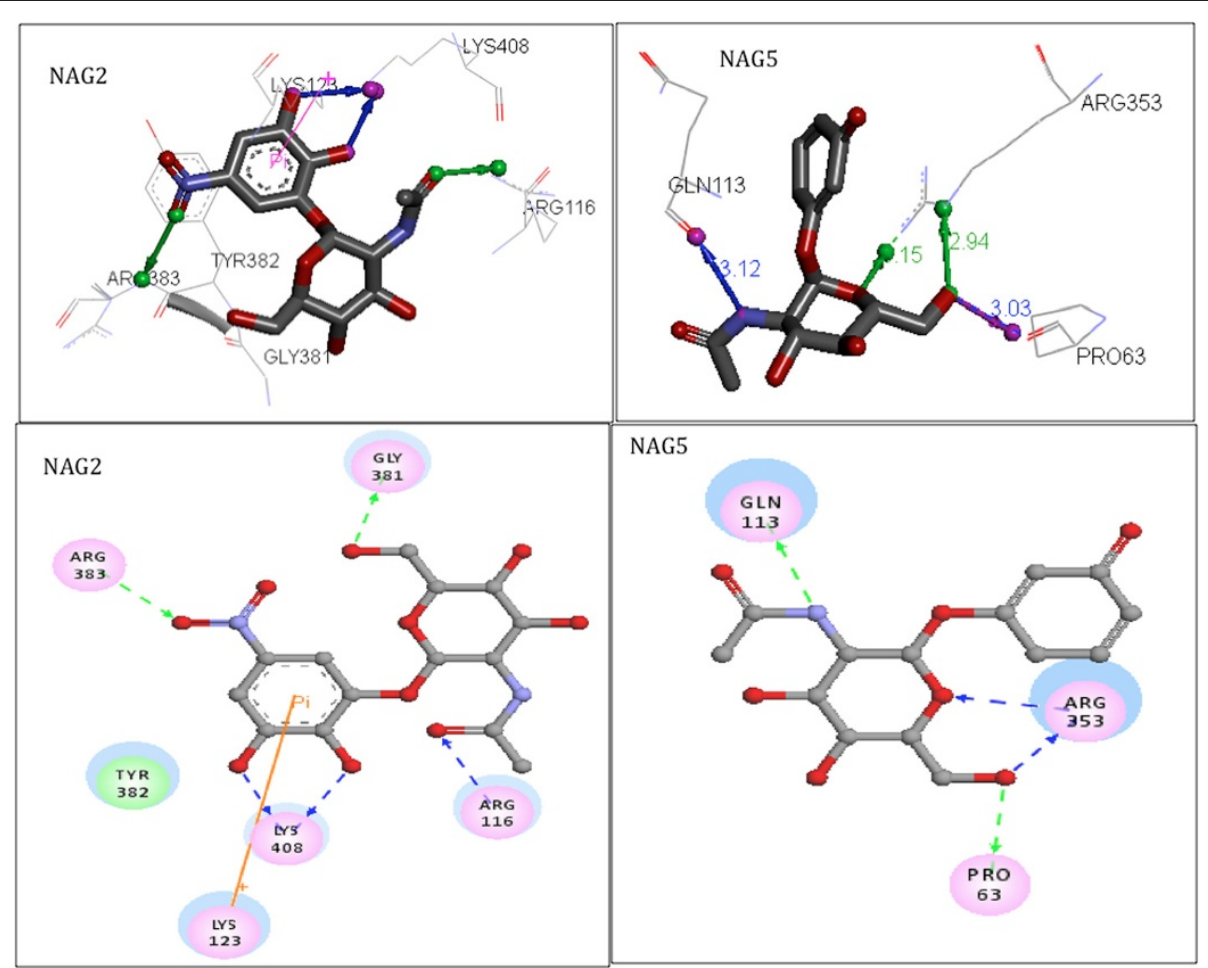

Figure 4 Interactions formed between compounds with NAG5 and NAG6 pyrophosphorylase enzyme. Green line: HBA, Blue Line: HBD, Rose Line: hydrophobic interactions and Yellow line: $\pi$-cation interaction. Visualization generated by the program Discovery Studio 3.5 . 


\section{Methods}

Initially, the previously built [14] UNAcP model was structurally aligned with the crystal structure of pyrophosphorylase with PDB code 1JV1 [16], whose active site was preserved, as shown by the structural alignment [23]. Next, the atomic coordinates of the substrate were transferred from the protein crystallographic 1JV1 to the UNAcP model. A redocking process was performed to verify the ability to reproduce the intermolecular interaction of the docking method. Next, a set of carbohydrate derivatives with $\mathrm{N}$-acetyl moiety (Figure 1 ) were docked against the UNAcP model. The docking studies were conducted using AutoDock Vina 1.1.2. The search algorithm used was Iterated Local Search Global Optimizer for global optimization. In this process, a succession of steps with a mutation and local optimization (the method of Broyden-Fletcher-Goldfarb-Shanno [BFGS]) were conducted, and each step followed the Metropolis criterion [24]. To explore all active sites, the researchers constructed a grid box, which was defined as a cube with the geometric center between $\mathrm{N}$-acetylglucosamine-1phosphate and UTP, with dimensions of $18 \times 14 \times 16 \AA$, spaced points of $1 \AA$ and $\mathrm{X}, \mathrm{Y}$ and $\mathrm{Z}$ coordinates of $-58.323,79.633$ and -18.926 , respectively.

The complexes formed in the docking step were minimized by SANDER routine using the AMBER 10 software [25]. The complexes between ligand and molecular targets were optimized by 500 cycles for each algorithm, steepest descent (SD) and conjugate gradient (GG), with spatial restriction of the ligand atoms of $500 \mathrm{kcal} / \mathrm{mol}$. This initial optimization aims to remove the interactions caused by molecular packing and improve the fit of the ligand in the protein, once the docking simulation considers the protein as a rigid structure. Finally, minimization of 3000 cycles (1500 SD and 1500 GG) was performed using the same specifications as above, but without spatial restriction.

Following the minimizing step, the complexes were submitted to molecular dynamics simulations (MD). The initial simulations were 100 picoseconds, varying the temperature until the system reached a final temperature of $300 \mathrm{~K}$. After the heating step, the complexes were submitted to MD of 8000 picoseconds at a constant temperature of $300 \mathrm{~K}$. All minimization and MD simulations were carried out using the Generalized Born implicit solvent model, with cut-off value of $14 \AA$. The results were analysed using Root-Mean-Square Deviation (RMSD) graph per simulation time.

The program ptraj was used to separate the remaining balance from the zone of the trajectory [26]. The use of the entire trajectory can generate less reliable results. The same program was used to calculate the average structure (MS). MS was subdivided into complex (сомP), protein (
3000 cycles of optimization. The results of this step were used to determine the binding energy through the following equation: Binding energy $=E_{\mathrm{COMP}}-\mathrm{E}_{\mathrm{PTN}}-\mathrm{E}_{\mathrm{LIG}}$.

\section{Competing interests}

We declare that there are no any competing interests.

\section{Authors' contributions}

All authors contributed equality for the development of the manuscript. MCSJ, SAA, AGN, AAD and AGT contributed with docking and molecular dynamics simulations, search for natural inhibitors, sequence of enzyme, high performance computation environment, design of inhibitors, analysis of results and elaboration of manuscript, respectively. All authors read and approved the final manuscript.

\section{Acknowledgements}

This work was supported by FINEP, CAPES, CNPq and FAPESB. We also thank the Programa de Pós-Graduação em Biotecnologia UEFS/FIOCRUZ. RJA has a research fellowship from CNPq-Brazil.

\section{Author details}

'Departamentos de Saúde, Feira de Santana 44031-460, Feira de Santana-BA, Brazil. ²Ciências Biológicas, Feira de Santana 44031-460, Feira de Santana-BA, Brazil. ${ }^{3}$ Tecnologia, Programa de Pós-Graduação em Biotecnologia, Universidade Estadual de Feira de Santana, Feira de Santana-BA 44031-460, Brazil. ${ }^{4}$ Universidade Federal de Minas Gerais, Faculdade de Farmácia, Departamento de Produtos Farmacêuticos, Av. Antônio Carlos, 6627, Pampulha 31270-901, Belo Horizonte, MG, Brazil. ${ }^{5}$ Laboratório de Modelagem Molecular, Programas de Pós-Graduação em Biotecnologia e Ciências Farmacêuticas, Campus Centro Oeste (CCO), Universidade Federal de São João Del-Rei, Divinópolis-MG 35501-296, Brazil.

Received: 6 December 2012 Accepted: 15 February 2013

Published: 5 March 2013

\section{References}

1. Pereira JL: First occurence of witches'broom disease in the principal cocoa-growins region of brazil. Trop Agric 1990, 67:188-189.

2. Muse RB, Collin HA, Isaac S, Hardwick K: Effects of the fungus Crinipellis perniciosa, causal agent of witche's broom disease, on cell and tissue cultures of cacao (Theobroma cacao L.). Plant Pathol 1996, 45:145-154.

3. CEPLAC: Panorama da economia mundial de cacau. http://www.ceplac.gov. br/Sinopse_Cacau/Panorama/producao-mundial.htm.

4. Medeiros FHV: A novel integrated method for management of witches'broom diseace in Cacao in Bahia. Brazil. Crop. Protection 2010, 29:704-711.

5. Costa JCB: Controle biológico da vassoura-de-bruxa do cacaueiro da Bahia, Brasil. In Biocontrole de doenças de plantas: uso e perspectivas. Edited by Bettiol W. Jaguariúna: Embrapa meio ambiente; 2009:245-266.

6. Oliveira ML, Luz EDMN: Vassoura-de-bruxa. In Identificação e manejo das principais doenças do cacaueiro no Brasil. Edited by Oliveira ML, Luz EDMN. Ilhéus: CEPLAC/CEPEC/SEFIT; 2005:15-33.

7. de Andrade DVG, Góes-Neto A, Comar Junior M, Taranto AG: Comparative modeling and QM/MM studies of cysteine protease mutant of Theobroma cacao. Int J Quantum Chem 2012, 112:3164-3168.

8. Pinheiro AAF, Taranto AG, Duarte AA, Góes-Neto A, da Hora Júnior BT, Pereira GAG, dos Santos Júnior MC, de Assis SA: Homology modeling studies of beta(1,3)-D-glucan synthase of Moniliophthora perniciosa. Int J Quantum Chem 2012, 112:3356-3363.

9. Andrade BS, Taranto AG, Góes-Neto A, Duarte AA: Comparative modeling of DNA and RNA polymerases from moniliophthora perniciosa mitochondrial plasmid. Theor Biol Med Model 2009, 6:1-2.

10. Dos Santos Junior MC, Taranto AG, Assis AS, Góes-Neto A: Homology modeling of pyrophosphorylase, enzyme involved in chitin pathway of moniliophthora perniciosa. Int J Bioinforma Res Appl (IJBRA) 2009, 5:133153.

11. Macedo VUM, Dos Santos Júnior Manoelito C, Souza CS, Galante RS, Andrade BS, Assis SA, Góes-Neto A, Taranto AG: Aspectos gerais do moniliophthora perniciosa (STAHEL) AIME \& PHILLIPS-MORA, O agente etiológico da vassoura-de-bruxa. Sitientibus. Série Ciências Biológicas 2009, 9:57-65 
12. Souza CS, Costa GGL, Uetanabaro APT, Pirovani CP, Pereira GAG, Cascardo JC De M, Taranto AG, Góes-Neto A: Identification and characterization of a class III chitin synthase gene of Monilliophthora perniciosa, the fungus that causes wtiches' broom disease of cacao. J Microbiol 2009, 47:431-440.

13. Herscovics A, Orlean P: Glycoprotein biosynthesis in yeast. FASEB J 1993, 7:540-550.

14. Santos Junior MC, Gonçalves PA, Taranto AG, Koblitz MGB, Góes-Neto A, Pirovani CP, Cascardo JCM, Cruz SH, Zingali RB, Pereira GAG, Dias CV, Assis AS: Purification, characterization and structural dertermination of UDP-N -Acetylglucosamine pyrophosphorylase produced by Moniliophthora perniciosa. J Braz Chem Soc 2011, 22:1015-1023.

15. Strominger JL, Smith MS: Uridine diphosphoacetylglucosamine pyrophosphorylase. J Biol Chem 1959, 234:1822-1827.

16. Peneff C, Ferrari $P$, Charrier V, Taburet $Y$, Monnier C, Zamboni V, Winter J, Harnois M, Fassy F, Bourne Y: Crystal structures of two human pyrophosphorylase isoforms in complexes with UDPGIc(Gal)NAc: role of the alternatively spliced insert in the enzyme oligomeric assembly and active site architecture. EMBO J 2001, 20:6191-6202.

17. Yamamoto K: Inhibition of UDP-N-acetylglicosamine pyrophosphorylase by uridine. BBA 1980, 614:367-372

18. Smith GS, Sternberg MJE: Prediction of protein-protein interactions by docking methods. Curr Opin Struc Bio 2002, 12:28-35.

19. Wong CF: Flexible ligand-flexible protein docking in protein kinases systems. BBA 2008, 1784:244-251.

20. Ewing TJA: DOCK 4.0: search strategies for automated molecular docking of flexible molecule databases. J. Compu-Aided Mol. Des 2001, 15:411-428.

21. Vieth M: Assessing search strategies for flexible docking. J Compt Chem 1998, 19:1623-1631

22. Rino JP, Studart N: Um potencial de interação para o estudo de materiais e simulações por dinâmica molecular. Quim Nova 2001, 24:838-845.

23. Maruyama D, Nishitani Y, Yuichi N, Tsuyoshi K, Akiko F, Takaaki M, Toshiyuk YO, Hisafumi YO, Toshiko MK: Crystal structure of uridine-diphospho-Nacetylglucosamine pyphosphosrylase from Candida albicans and catalytic reaction mechanism. J Biol Chem 2007, 282:17221-17230.

24. Trott O, Olson AJ: AutoDock Vina: improvising the speed and accuracy of docking with a new scoring function, efficient optimization and multithreading. J Comp Chem 2010, 31:455-461.

25. Case DA, Darden TA, Cheatham TE III, Simmerling CL, Wang J, Duke RE, Luo R, Walker RC, Zhang W, Merz KM, Roberts B, Hayik S, Roitberg A, Seabra G, Swails J, Goetz AW, Kolossvai I, Wong KF, Paesani F, Vanicek J, Wolf RM, Liu J, Wu X, Brozell SR, Steinbrecher T, Gohlke H, Cai Q, Ye X, Wang J, Hsieh M-J, Cui G, Roe DR, Mathews DH, Seetin MG, Salomon-Ferrer R, Sagui C, Babin V, Luchko T, Gusarov S, Kovalenko A, Kollman PA: AMBER 10. San Francisco: University of California; 2008

26. Krumrine J: Principles and methods of docking and ligand design. In Strucutural Bioinformatics. Edited by Bourne PE, Helge W. New Jersey: Wiley; 2003:443-476.

doi:10.1186/1752-153X-7-48

Cite this article as: Junior et al:: Structure-based drug design studies of UDP- $N$-acetylglucosamine pyrophosphosrylase, a key enzyme for the control of witches' broom disease. Chemistry Central Journal 2013 7:48

Publish with ChemistryCentral and every
scientist can read your work free of charge
"Open access provides opportunities to our
colleagues in other parts of the globe, by allowing
anyone to view the content free of charge."
W. Jeffery Hurst, The Hershey Company.
- available free of charge to the entire scientific community
- peer reviewed and published immediately upon acceptance
- cited in PubMed and archived on PubMed Central
- yours - you keep the copyright
Submit your manuscript here:
http://www.chemistrycentral.com/manuscript/

